\title{
Should Attendance Be Required in Lecture Classrooms in Dental Education? Two Viewpoints
}

\author{
Viewpoint 1: Attendance in the Lecture Classroom Should Be \\ Required
}

\author{
Christopher W. Cutler, DDS, PhD; Mary Parise, DDS; Ana Lucia Seminario, DDS, PhD, \\ $\mathrm{MPH}$
}

\section{Viewpoint 2: Attendance Should Not Be Required in the Lecture Classroom}

\begin{abstract}
Maria Jose Cervantes Mendez, DDS, MS; Wilhelm Piskorowski, DDS; Renato Silva, DDS, MS, PhD

Abstract: This Point/Counterpoint discusses the long-argued debate over whether lecture attendance in dental school at the predoctoral level should be required. Current educational practice relies heavily on the delivery of content in a traditional lecture style. Viewpoint 1 asserts that attendance should be required for many reasons, including the positive impact that direct contact of students with faculty members and with each other has on learning outcomes. In lectures, students can more easily focus on subject matter that is often difficult to understand. A counter viewpoint argues that required attendance is not necessary and that student engagement is more important than physical classroom attendance. This viewpoint notes that recent technologies support active learning strategies that better engage student participation, fostering independent learning that is not supported in the traditional large lecture classroom and argues that dental education requires assimilation of complex concepts and applying them to patient care, which passing a test does not ensure. The two positions agree that attendance does not guarantee learning and that, with the surge of information technologies, it is more important than ever to teach students how to learn. At this time, research does not show conclusively if attendance in any type of setting equals improved learning or ability to apply knowledge.
\end{abstract}

Dr. Cutler is Professor and Chair, Department of Periodontics and Associate Dean for Research, Dental College of Georgia, Augusta University; Dr. Parise is Program Director of Advanced Education in General Dentistry, University of Detroit Mercy School of Dentistry; Dr. Seminario is Visiting International Dentist Program Director, Department of Pediatric Dentistry, University of Washington; Dr. Cervantes Mendez is Program Director of Pediatric Dentistry, University of Texas Health Science Center at San Antonio School of Dentistry; Dr. Piskorowski is Assistant Dean for Community-Based Dental Education, University of Michigan School of Dentistry; and Dr. Silva is Chair, Department of Endodontics, The University of Texas at Houston School of Dentistry. Direct correspondence to Dr. Maria Jose Cervantes Mendez, Department of Developmental Dentistry, University of Texas Health Science Center at San Antonio School of Dentistry, Mail Code 7888, 7703 Floyd Curl Drive, San Antonio, TX 78229-3900; 210-450-3514; cervantesmen@uthscsa.edu.

Keywords: dental education, teaching method, educational technology, educational measurement, computer-assisted instruction, active learning, lecture

Submitted for publication 3/7/16; accepted 6/20/16

$\mathrm{D}$ oes required lecture attendance make a difference in the learning experience of contemporary dental students? The traditional delivery of information via lecture in a large auditorium-style classroom has been the foundation of predoctoral dental education for many years. As millennial students fill our classrooms, we have to ask ourselves if traditional teaching practices are still valid or if there is a need to transform the educational model. Should this new model enforce required attendance at lectures or not? This Point/Counterpoint presents two viewpoints on this question. 


\section{Viewpoint 1: Attendance in the Lecture Classroom Should Be Required}

We believe attendance in the lecture classroom in dental schools should be required. In dental education, mandatory attendance at lectures has been debated, particularly as the number of students grows and the number of full-time faculty members does not match that growth rate. ${ }^{1,2}$ More and more is expected of dental faculty members in terms of research, teaching (didactic and clinical), and administrative responsibilities with less time allotted for teaching. Promotion and tenure committees focus more on scholarly output than teaching. Teaching is time-intensive and can interfere with one's ability to complete scholarly activity. The value of traditional lecture, sometimes called "the sage on the stage" format, in adequately preparing dentists and other health care professionals for decision making and problem solving is increasingly being called into question. ${ }^{3,4}$ However, many students across the health sciences have reported feeling that e-materials, recorded lectures, and access to printed lecture materials should not replace lecture attendance. ${ }^{5}$ Critical thinking, writing skills, and the integration and translation of didactic information into clinical decisions are essential skills for the health sciences. Increasingly evident is a rise in absenteeism among college students. It is plausible that this trend negatively impacts the learning curve of future health care professionals. ${ }^{5}$

This viewpoint supports the important role that lecture attendance plays in dental education. While studies that specifically address predoctoral dental education in this regard are scarce, there is evidence from studies in specialties indicating that traditional teaching methods will not yet be replaced by other technologies such as video podcasts, for example, although these new technologies play an important role in reinforcing learning. ${ }^{5,6} \mathrm{~A}$ study of postdoctoral dental students found a correlation between lecture attendance and performance. ${ }^{7}$ Our discussion mostly applies to dental education the findings gained from studies of undergraduate students and medical students. ${ }^{8-12}$

There are several benefits to lecture attendance. It fosters direct contact among students and between students and faculty members. In lectures, faculty members can place emphasis on essential topics and have the opportunity for bidirectional discussion and immediate feedback with questions. Lecture format is the most efficient way to transfer material to the largest group of students, and students have grown accustomed to attending lectures throughout their education. One common anecdotal complaint among faculty members is that unless attendance is required, many students do not show up. Even if they do, many are observed shopping online or engaging in other activities on their laptops. One study found that the most frequently cited reason for failure of second-year dermatology medical students to attend a lecture was availability of online lectures (35\%), followed by preference for self-study (26\%) and inconvenience of attending (24\%). ${ }^{11}$

What then is the evidence for the value of compulsory lecture attendance versus optional attendance in terms of learning outcomes? A recent meta-analysis of the relationship of college class attendance with grades revealed that attendance had strong significant relationships with class grades $(\mathrm{k}=33, \mathrm{~N}=9,243, \mathrm{p}=0.41) .{ }^{8}$ Indeed, absenteeism has been linked to underperformance in medical school. ${ }^{7}$ Similarly, attendance in a human physiology course in the second year of pharmacy, nursing, physical education, and dental hygiene programs was linked to a small but statistically significant correlation with higher examination scores. ${ }^{13}$ Mandatory attendance in an economics course was positively linked to higher student performance. ${ }^{14}$

Perhaps more important than the question of mandatory attendance is the need to focus efforts on making our lectures more attractive and substantial for students to attend (Table 1). Recent research in education proposed several tools to engage participants and improve the delivery of faculty members' messages, so that students are learning what we are targeting in our courses. ${ }^{15,16}$ With the rapid media growth impacting how younger generations interact and learn, we should apply Internet-related tools to our classrooms. There may be novel ways to use the Internet to develop interprofessional education with our colleagues in medicine, education, or psychology, for example.

While there is evidence to support the value of lecture attendance in dental education, we need to rethink the classic paradigm by providing creative ways to engage students. Although we have cited several studies that support improved outcomes of attendance based on test scores, we question if a test score or performance is a true measure of understanding. We are skeptical of the ability of a test score or performance to correlate with the ability to apply 
Table 1. Advantages of the argument for required attendance in lecture classrooms

Advantage

Implications

1. Simplifies policies.

2. All students receive the same information.

3. Immediate feedback on understanding.

4. Lectures used in building block format.
Grading includes attendance uniformly.

Limits complaints that "you never covered that."

Simplifies curriculum reviews.

Use of clickers facilitates teaching, identifying what was missed or misunderstood.

Application of material can be immediately evaluated.

Instructor can structure course throughout semester. knowledge in a clinical setting, which is the goal of educating a health care professional.

\section{Viewpoint 2: Attendance Should Not Be Required in Lecture Classrooms}

Students' absence in lecture classrooms is currently very noticeable and raises the important question: what are students trying to tell us? We believe that advances in technology have resulted in a paradigm shift in dental education, and class attendance is not associated with improved academic performance. Student engagement is more important than physical classroom attendance because as students participate in their own learning, they become lifelong learners and are more satisfied with their academic experience.

Attendance at lectures has been a topic of discussion for decades; however, little is known about the impact of class attendance and learning preferences on academic performance. Large classes can be intimidating for students and reduce the likelihood of engagement, inquiry, and feedback. These larger courses tend to be conducted as "lecture-centric," with limited opportunities for students to interact with the instructor. Educational practice and educational research are not aligned. Current educational practice relies heavily on information transmission or content delivery to learners. Yet one study found that delivery was only a minor part of learning. ${ }^{17}$

The use of technology to capture the audio and visual elements of lectures, to engage students in course concepts, and to provide feedback to assignments has become a mainstream practice in higher education through podcasting and lecture-capturing mechanisms. ${ }^{18}$ However, the increasing availability of technology-enhanced educational materials may have a negative impact on lecture attendance. ${ }^{19}$ Technology has had a significant impact on the way we teach and the way students learn. The introduction of online databases and e-readings has made physical visits to the library unnecessary for acquiring most documents. In one study, students questioned the need to attend lectures because they can access the information electronically online..$^{20}$

One study in India found that class attendance was not associated with improved academic performance, especially when engaged learning sessions were offered, such as online resources or problembased learning. ${ }^{11}$ Studies have found that university students often do not attend lectures or tutorials because they are too busy, are sick, are working, are bored, have technology alternatives, or do not like the teacher. ${ }^{19,20}$ According to those studies, excluding health and lifestyle factors, the most important influences on attendance were student attitudes about the topic - for example, "the topic was boring" and "I don't like the subject." A recent study in medicine reported that the most frequently cited reason for attending classes was social expectation (96\%), whereas the least cited was learning well in a classroom-type setting (65\%). ${ }^{11}$ The top reasons cited by students for not attending classes in that study were availability of lectures online (35\%), preference for individual study outside the classroom setting $(26 \%)$, and the inconvenience of traveling to class $(24 \%)$.

Active learning strategies like problem-based learning and flipped classrooms have been found to be far more effective in delivering information and helping students process the concepts while keeping them motivated. ${ }^{21}$ Those learning models support learning at different levels such as having access to the information before and after lecture and allowing study to occur at an individualized pace, thus providing the opportunity to make use of class time previously used in lecture to apply concepts that solidify students' knowledge (Table 2). 


\section{Table 2. Advantages of the argument against required attendance in lecture classrooms}

Advantage Implications

1. Students' satisfaction is higher.

Model supports learning at different levels and speeds.

Allows flexibility to accommodate students' health and lifestyle factors.

2. Promotes active learning.

Physical presence in a classroom is a minor point in learning.

3. Efficient use of time.

Flips learning from faculty delivery to a student-oriented model.

Increased use of technology enhances access to educational materials.

We should also ask if lectures are primarily meant to prepare students for tests and exams or if lectures are a useful means of instruction helping to create a balanced and informed person. ${ }^{22}$ Class attendance has not been associated with improved academic performance. One study found a positive relationship between online note use and examination performance. ${ }^{23}$ supporting the idea that students may be able to successfully compensate by viewing online lecture resources when unable to attend class. Another study reported that students who preferred to learn by watching online videos had a higher level of performance than those who did not prefer to learn this way. ${ }^{11}$

Controversy about required lecture attendance is supported by conflicting evidence: one study, for example, found an association between student attendance and grade outcomes, ${ }^{24}$ while another found that access to electronic materials did not influence students' choices. ${ }^{19}$ Putting this controversy to rest would require a randomized controlled trial of learning outcomes for two groups of dental students: those required to attend lectures and those that did not attend lectures.

As educators, we strive to help our students become lifelong learners. There is a constant surge of new information and technologies, and it has become obvious that it is more important to teach students how to learn through active learning than to merely memorize facts. ${ }^{25}$ In order to achieve this goal, there is a need to transform dental education from a teacher-centered model to a student-oriented model, in which lecture attendance is not mandatory but is part of the process.

\section{REFERENCES}

1. John V, Papageorge M, Jahangiri L, et al. Recruitment, development, and retention of dental faculty in a changing environment. J Dent Educ 2010;75(1):82-9.

2. Hamamoto D, Farrar S, Caplan D, et al. Use of shared faculty in U.S. and Canadian dental schools. J Dent Educ 2012;77(3):264-75.
3. Walton J, Clark D, Glick N. An outcomes assessment of a hybrid-PBL course in treatment planning. J Dent Educ 1997;61(4):361-7.

4. McLaughlin J, Roth M, Glatt D, et al. The flipped classroom: a course redesign to foster learning and engagement in a health professions school. Acad Med 2014;89:236-43.

5. McCann A, Schneiderman E, Hinton R. E-teaching and learning preferences of dental and dental hygiene students. J Dent Educ 2010;74(1):65-78.

6. Schreiber ES, Fukuta J, Gordon F. Live lecture versus video podcast in undergraduate medical education: a randomized controlled trial. BMC Med Educ 2010;10:68.

7. El Tantawi M. Factors affecting postgraduate dental students' performance in a biostatistics and research design course. J Dent Educ 2009;73(5):614-23.

8. Crede M, Roch S, Kieszczynka U. Class attendance in college: a meta-analytic review of the relationship of class attendance with grades and student characteristics. Rev Educ Res 2010;80:272-95.

9. Deane R, Murphy D. Student attendance and academic performance in undergraduate obstetrics/gynecology clinical rotations. JAMA 2013;310:2282-8.

10. Dhaliwal U. Absenteeism and underachievement in finalyear medical students. Natl Med J India 2003;16:34-7.

11. Eisen D, Schupp C, Isseroff R, et al. Does class attendance matter? Results from a second-year medical school dermatology cohort study. Int J Dermatol 2015;54:807-16.

12. Martin S, Way D, Verbeck N, et al. The impact of lecture attendance and other variables on how medical students evaluate faculty in a preclinical program. J Assoc Am Med Coll 2013;88:972-7.

13. Hammen C, Kelland J. Attendance and grades in a human physiology course. Am J Physiol 1994;1:S105-8.

14. Marburger D. Does mandatory attendence improve student performance? J Econ Educ 2006;37:148-55.

15. Liebert C, Lin D, Mazer L, et al. Effectiveness of the surgery core clerkship flipped classroom: a prospective cohort trial. Am J Surg 2016;211:451-7.

16. Jones R, Maramba I, Boulos M, Alexander T. Use of live interactive webcasting for an international postgraduate module in e-health. Case Study Eval 2009;11:e46.

17. Van der Vieuten CEW. What would happen to education if we take education evidence seriously? Perspect Med Educ 2014;3:222-32.

18. Holbrook J, Dupont C. Profcasts and class attendance: does year in program matter? Biosci Educ 2009;13:c2.

19. Billings-Gagliardi SM. Student decisions about lecture attendance: do electronic course materials matter? Acad Med 2001;82(Suppl). 
20. Massingham P, Herrington T. Does attendance matter? An examination of student attitudes, participation, performance, and attendance. J Univ Teach Learn Pract 2006;3:3.

21. Bishop J, Verleger M. The flipped classroom: a survey of the research. Washington, DC: American Society for Engineering Education, 2013.

22. Walbeek VC. Does lecture attendance matter? Some observations from a first-year economics course at the University of Cape Town. S Afr J Econ 2004;72.
23. Grabe MK. Optional student use of online lecture resources: resource preferences, performance, and lecture attendance. J Comput Assist Learn 2008;24:1-10.

24. Chamberlain J. Grades and attendance: is there a link between them with respect to first-year undergraduate criminology students? Educ Res Rev 2012;7:5-9.

25. Prince M. Does active learning work? A review of the research. J Eng Educ Wash 2004;93. 